\title{
Using 3D photogrammetry from ROV video to quantify cold- water coral reef structural complexity and investigate its influence on biodiversity and community assemblage
}

\author{
David M. Price ${ }^{1,2}$ (D) Katleen Robert $^{3} \cdot$ Alexander Callaway $^{4} \cdot$ Claudio Lo lacono $^{1} \cdot$ \\ Rob A. Hall ${ }^{5}$ Veerle A. I. Huvenne ${ }^{1}$
}

Received: 18 December 2018/Accepted: 5 June 2019/Published online: 15 June 2019

(c) The Author(s) 2019

\begin{abstract}
Fine-scale structural complexity created by reefbuilding coral in shallow-water environments is influential on biodiversity, species assemblage and functional trait expression. Cold-water coral reefs are also hotspots of biodiversity, often attributed to the hard surface and structural complexity provided by the coral. However, that complexity has seldom been quantified on a centimetric scale in coldwater coral reefs, unlike their shallow-water counterparts, and has therefore never been linked in a similar way to the reef inhabitant community. Structure from motion techniques which create high-resolution 3D models of habitats from sequences of photographs is being increasingly utilised, in tandem with 3D spatial analysis to create useful 3D metrics, such as rugosity. Here, we demonstrate the use of ROV
\end{abstract}

Topic Editor Morgan S. Pratchett

Electronic supplementary material The online version of this article (https://doi.org/10.1007/s00338-019-01827-3) contains supplementary material, which is available to authorized users.

\section{David M. Price}

D.M.Price@ soton.ac.uk

1 National Oceanography Centre, University of Southampton, Waterfront Campus, European Way,

Southampton SO14 3ZH, UK

2 Ocean and Earth Science, University of Southampton, Waterfront Campus, European Way, Southampton SO14 3ZH, UK

3 Fisheries and Marine Institute of Memorial University of Newfoundland, St. John's, NL A1C 5R3, Canada

4 Centre for Environment, Fisheries and Aquaculture Science, Pakefield Rd, Lowestoft NR33 0HT, UK

5 Centre for Ocean and Atmospheric Sciences, School of Environmental Sciences, University of East Anglia, Norwich Research Park, Norwich NR4 7TJ, UK video transect data for 3D reconstructions of cold-water coral reefs at depths of nearly $1000 \mathrm{~m}$ in the Explorer Canyon, a tributary of Whittard Canyon, NE Atlantic. We constructed 40 3D models of approximately 25 -m-length video transects using Agisoft Photoscan software, resulting in subcentimetre resolution reconstructions. Digital elevation models were utilised to derive rugosity metrics, and orthomosaics were used for coral coverage assessment. We found rugosity values comparable to shallow-water tropical coral reef rugosity. Reef and nearby non-reef communities differed in assemblage composition, which was driven by depth and rugosity. Species richness, epifauna abundance and fish abundance increased with structural complexity, being attributed to an increase in niches, food, shelter and alteration of physical water movement. Biodiversity plateaued at higher rugosity, illustrating the establishment of a specific reef community supported by more than $30 \%$ coral cover. The proportion of dead coral to live coral had limited influence on the community structure; instead, within-reef patterns were explained by depth and rugosity, though our results were confounded to a certain extent by multicollinearity. Fine-scale structural complexity appeared to be integral to local-scale ecological patterns in cold-water coral reef communities.

Keywords Cold-water coral - Structure from motion . Reef community $\cdot$ Structural complexity $\cdot$ Habitat threshold · Rugosity

\section{Introduction}

Some colonial Scleractinian cold-water corals, such as Lophelia pertusa (recently synonymised to Desmophyllum pertusum (Addamo et al. 2016)), Madrepora oculata and 
Solenosmillia variablis, are capable of forming complex 3D reef structures, ranging from patchy cover to massive carbonate mounds (Wilson 1979; Wheeler et al. 2007). Cold-water coral reefs are predominantly found on continental slopes, seamounts and in fjords, but increasing evidence suggests submarine canyons also provide an important habitat (Orejas et al. 2009; Huvenne et al. 2011; De Mol et al. 2011; Lo Iacono et al. 2018). Due to their complex terrain, submarine canyons may provide important refugia for cold-water coral assemblages (Huvenne et al. 2011) that are vulnerable to destructive fishing practices elsewhere (Fossa et al. 2002; Davies et al. 2007; Althaus et al. 2009; Huvenne et al. 2016a).

Reef-building cold-water corals are autogenic ecosystem engineers according to the definition of Jones et al. 1994, and like shallow-water coral reefs, cold-water coral reefs are considered to be hotspots for biodiversity. Coldwater coral reefs support diverse habitat specific communities of epifauna and infauna (Jonsson et al. 2004; Mortensen and Fosså 2006; Henry and Roberts 2007; Bourque and Demopoulos 2018), with enhanced biodiversity and benthic biomass compared to adjacent substrate (Van Oevelen et al. 2009). For example, Shannon-Wiener indices of taxa associated with cold-water coral reefs on the Faroe shelves (North Atlantic) were approximately 5.5, a value which is comparable with shallow-water reef biodiversity (Jensen and Frederiksen 1992). This biodiversity is associated with sessile and vagile taxa alike (Jonsson et al. 2004). Living portions of the reef harbour fewer, more specialised species (Mortensen and Fosså 2006; Cordes et al. 2008), whilst the bare hard substrate of dead coral skeleton is often cited as a primary driver of reef biodiversity (Henry and Roberts 2015). In addition, the structural complexity of the 3D framework provided by the coral skeleton is also considered an important variable contributing to cold-water coral reef assemblage and biodiversity (Jonsson et al. 2004; Cordes et al. 2008; Robert et al. 2017).

Coral reef structural complexity influences marine biodiversity and community structure at multiple scales (Friedlander and Parrish 1998; Gratwicke and Speight 2005; Wilson et al. 2007; Graham and Nash 2013; Richardson et al. 2017). Broad-scale terrain rugosity has been cited as a driver of deep-sea biodiversity (Robert et al. 2015) and cold-water coral distribution (Lo Iacono et al. 2018). However, measuring fine-scale complexity of deepsea habitats at a similar scale to that in shallow-water coral reef research is problematic owing to the difficulty of sampling at depth. Yet, based on qualitative observations, it is generally accepted that deep-sea benthic fish benefit from fine-scale structural complexity (Roberts et al. 2005; Söffker et al. 2011; Purser et al., 2013). Invertebrates also benefit from structural complexity, for example, Stevenson et al. (2015) inferred the 3D structure created by cold-water coral was utilised by Cidaris cidaris in order to escape predation. At these fine scales, it is thought that the provision of a physically heterogeneous habitat offers multiple niches that organisms can utilise for shelter and/or feeding (Graham and Nash 2013). Structural complexity can alter hydrodynamic properties such as current velocity, shear and turbulence, subsequently providing additional microhabitats (Buhl-Mortensen et al. 2010), influencing larval entrainment (De Clippele et al. 2018), larvae retention (Boxshall 2000; Harii and Kayanne 2002), suspension feeder feeding efficiency (Purser et al. 2010; Orejas et al. 2016) and infauna diversity (Bourque and Demopoulos 2018).

Multibeam echosounders (MBES) mounted on remotely operated vehicles (ROVs) can acquire sub-metre resolution bathymetry of cold-water coral reefs (Huvenne et al. 2011; Foubert et al. 2011; De Clippele et al. 2017; Lim et al. 2018). Yet, despite these novel techniques, a general lack of complexity measurements of cold-water coral reef framework (centimetric resolution) represents a knowledge gap which can be mitigated through the use of novel image analysis techniques. Structure from motion (SfM), a form of 3D photogrammetry, is becoming more prevalent in marine imaging research in order to derive terrain variables such as coral reef rugosity (Leon et al. 2015; Storlazzi et al. 2016). This technique opens opportunities for the extraction of a plethora of fine-scale terrain variables that may contribute to the understanding of functioning of deep-sea habitats, such as cold-water coral assemblages (Robert et al. 2017). However, relatively few SfM surveys have been carried out in deep-sea habitats due to the difficulty of acquiring controlled images at depth with additional implications of strong currents and water column turbidity often associated with cold-water coral reef locations (Mienis et al. 2007; Davies et al. 2009; Duineveld et al. 2012). Unmanned underwater vehicles (ROVs, autonomous underwater vehicles and towed platforms), however, can collect suitable images and data to implement SfM techniques (Johnson-Roberson et al. 2010; Robert et al. 2017; Purser et al. 2018).

Cold-water coral reefs are vulnerable to bottom contact fishing activities, and are thus classified as a 'Vulnerable Marine Ecosystem (VME)' (United Nations General Assembly Resolution 61/105), of which structural complexity is a defining characteristic (FAO, 2009). Yet the assignment threshold of VME status to cold-water coral reefs based on imagery is ambiguous, in part due to the lack of prerequisite information about the density at which a group of separate colonies alter the environment enough to form a habitat with distinct communities. Coral coverage values of more than 15 or $60 \%$ to detect a distinct coral reef or 'coral framework' habitat have been used in previous 
studies (Rowden et al. 2017, Vertino et al. 2010), but no quantified consensus exists. This may be due to a lack of precise coral coverage and the associated structural complexity information required to identify a distinct habitat and VME threshold. As well as destructive fishing practices mechanically reducing the reef structure, shallowing aragonite saturation horizon (Turley et al. 2007) geochemically degrades living and dead portions of the reef 3D structure (Hennige et al. 2015). These anthropogenic impacts would reduce the structural complexity with repercussions for the associated fauna and VME status, further highlighting a need to quantify reef characteristics on a framework scale.

In this study, we provide rugosity metrics from 3D reconstructions of cold-water coral reefs using SfM with video data collected from an ROV. We aim to (1) quantify the structural complexity introduced by cold-water coral reef patches (2) identify the role of structural complexity in driving biodiversity and assemblage composition (3) use fine-scale information to identify the threshold of coral cover and structural complexity required to form a distinct cold-water coral reef habitat and provide evidence for VME characteristics.

\section{Methodology}

\section{Study area}

Explorer Canyon is a tributary of the Whittard Canyon system in the North-East Atlantic (Fig. 1). The canyon lies within the British exclusive economic zone (EEZ) and forms part of The Canyons Marine Conservation Zone (MCZ) (Ministerial order 2013) which was designated based on the occurrence of deep-sea bed and cold-water coral reef habitats in accordance with the UK Marine and Coastal Access Act (2009). The canyon system is subject to energetic internal wave activity (Vlasenko et al. 2014; Hall et al. 2017; Aslam et al. 2018), upwelling (Porter et al. 2016) and provides suitable habitats for cold-water coral (Huvenne et al. 2011; Robert et al. 2017). Davies et al. (2014) located reef-building scleractinians on a spur midway up the Explorer Canyon branch at 795-940 m depth.

\section{Video survey and data preparation}

The data for this study were collected during a survey as part of the Expedition JC125 aboard the RRS James Cook (Huvenne et al. 2016b). The ROV Isis was used to conduct a video transect starting from the thalweg of the canyon and ascending along the Explorer Canyon slope and scarp (Fig. 1). One frame per second was extracted from a highdefinition obliquely angled camera (HDSCI) mounted on the ROV, using Quicktime 7 Pro (Apple Inc.). The transect was divided into $25-\mathrm{m}$ sections or sub-transects, estimated from the horizontal distance travelled based on the Sonardyne ultra-short baseline (USBL) positioning system and the corresponding images were extracted for 3D reconstruction. Sections of $25 \mathrm{~m}$ were chosen as reconstructions along a single line tended to accumulate positioning error with increasing distance, and thus, longer subtransects became unreliable. Secondly, shorter sections might not have encompassed enough area for robust faunal counts of low density organisms such as fish. Finally, 25-m transects have also been used in shallow-water coral reef rugosity research (Friedlander and Parrish 1998), thus aiding comparison with previous work.

The sloping and complex topography of the canyon prevented true nadir camera angle although the slightly angled ROV camera against the slope was determined to be favourable for 3D reconstructions during preliminary analysis. Whilst having the camera orthogonal to the subject is not a prerequisite for reconstructions, it is beneficial to ensure as much of the terrain is captured accurately as possible (Kwasnitschka et al. 2013). The images were manually assessed for lapses in quality and removed where necessary. De-interlacing of the frames was performed in Adobe Photoshop CS6.

\section{Reconstruction}

The images were imported into Agisoft Photoscan Professional (v. 1.3.4.5067). The final step before processing involved masking the images to remove parts of the ROV equipment that were captured in the frame or black background beyond the light, improving image distortion residuals significantly. Optical aberrations caused by the water/glass interface were not calibrated due to lack of available information. However, Young et al. (2017) found that non-calibrated cameras produced accurate and precise reconstructions to a centimetric scale, suggesting Agisoft Photoscan performs adequately with non-calibrated cameras and distorted images. Each frame was paired with its USBL position for georeferencing (performed in $\mathrm{R}$ version 3.3.2), and lasers spaced $10 \mathrm{~cm}$ apart were used as a reference scale at multiple flat locations within each reconstruction.

The workflow was carried out as specified by Agisoft Photoscan Professional, using a 16 core, 64 GB High Performance Computing (IRIDIS) node with two NVIDIA K20 graphics processors. High-quality alignment via generic pre-selection was chosen. High-quality dense clouds were created and optimised for scale and georeferenced, then reprocessed, followed by manual editing to remove outliers and noise. The models were screened visually for distortions and large georeferencing errors. The outputs 


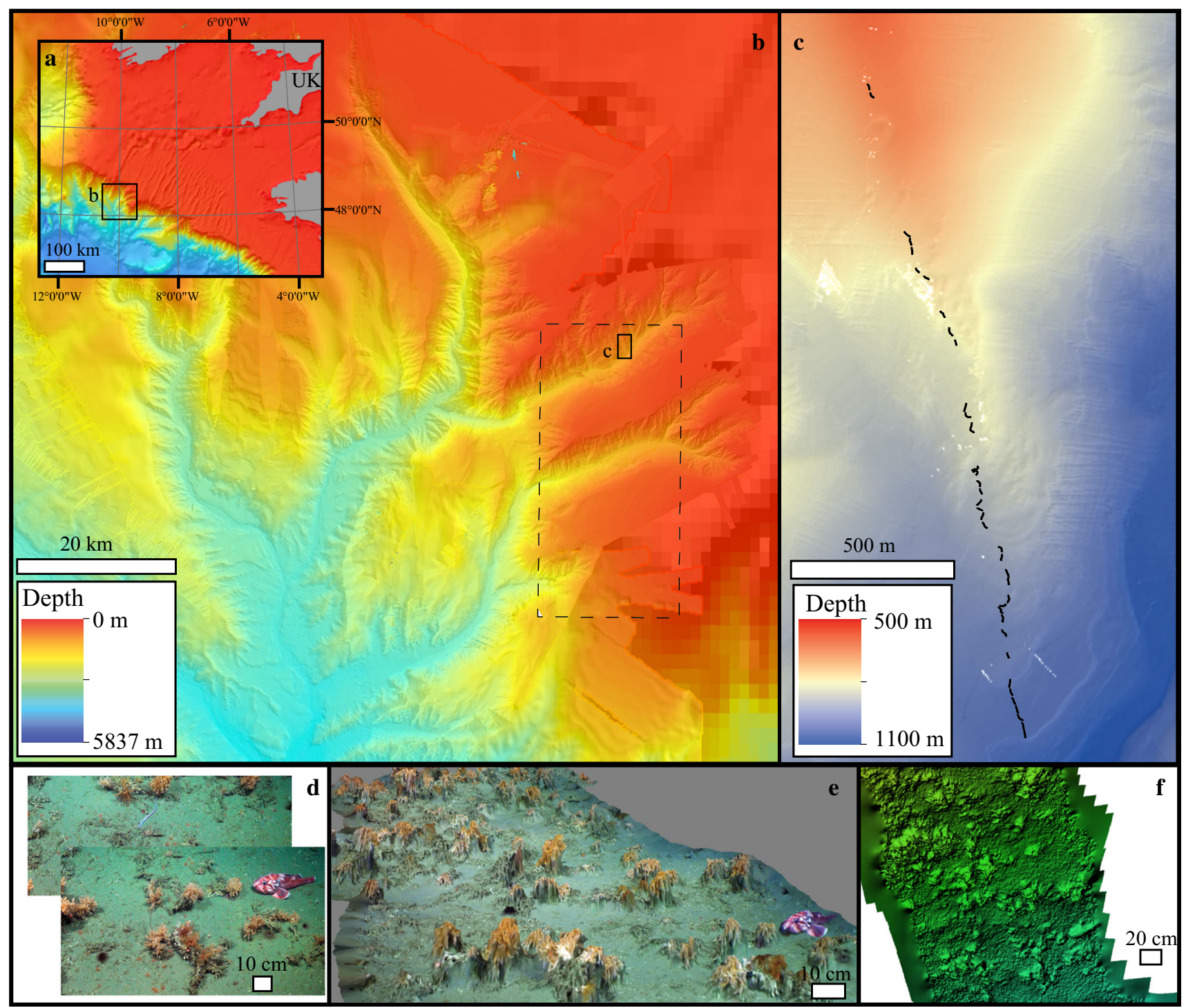

Fig. 1 a Geographical location, global bathymetry (GEBCO), with the Eastern Whittard Canyon outlined. b Eastern Whittard Canyon with the Marine Conservation Zone boundary (dashed rectangle) and study site outlined (c). c Spur in the Explorer Canyon (North part of

were exported as digital elevation models (DEM) at a standard $5 \mathrm{~mm}$ pixel size for terrain analysis and orthomosaics at the highest resolution (predominantly $<2 \mathrm{~mm}$ per pixel) to quantify coral coverage. Where gaps in the DEM were caused by tall coral colonies obstructing the camera view, these were addressed through interpolation (as used by Leon et al. 2015).

\section{Biodiversity}

The 'SCORPIO' camera mounted on Isis recorded video footage in high definition which was used to count the organisms present using OFOP (Ocean Floor Observation Protocol) software. The SCORPIO camera was utilised as
MCZ). Black lines denote approximate 3D reconstructed subtransects. d Example image sequences. e 3D reconstruction of a reef transect. f Digital elevation model of the coral reef

it was installed in a static position with fixed zoom for a consistent standardised analysis which was within the field of view of the HDSCI video footage. Organisms were recorded as morphospecies and then identified to the lowest possible taxonomic resolution. All species within the time frames of the image sequences used for reconstructions were binned to the respective sub-transect and standardised to sub-transect lengths (individuals per metre). Fish counts (for fish abundance only) were obtained from the HDSCI camera due to its wider field of view, providing a larger area for fish observations and all species were concatenated as few were observed (Purser et al. 2013). Species richness, Shannon-Wiener index, total abundance and fish abundance were used for univariate data analysis. Reef-building 
species were not included in community assemblage analysis due to their role as an independent variable in this study.

\section{Rugosity}

The DEMs were imported into ArcMAP 10.5 and analysed using the Benthic Terrain Modeller tool (BTM; Wright et al. 2005). As the transect traversed a canyon slope, vector ruggedness measure (VRM) from the BTM was utilised as a measure of rugosity as this method decoupled ruggedness from slope angle (Sappington et al. 2007). To asses any measurement scale-dependent relationships, VRM was calculated at different neighbourhood scales $(1.5,3.5,5.5,7.5,9.5,11.5,13.5,15.5,17.5$ and $19.5 \mathrm{~cm})$, to investigate a full range of scales from individual polyps to colony scales. The mean ruggedness index value for each reconstruction was calculated to identify any scaledependent relationships.

A standard quantitative survey of shallow-water coral reef structural complexity is traditionally carried out using a chain laid out over the reef, and assessing the ratio of chain length/horizontal length to produce a rugosity index ratio (Graham and Nash 2013). Rugosity index ratio values were calculated along a line through the middle of each sub-transect (for the full length), using the following formula in order to replicate the chain rugosity method:

Rugosity index ratio $=\frac{3 \mathrm{D} \text { line length }}{2 \mathrm{D} \text { line length }}$

The structural complexity measure that had the strongest relationship with coral cover and biodiversity was used in subsequent biodiversity and community assemblage analysis.

\section{Substrate classification}

A custom ImageJ macro-code was used to randomly plot 250 points across each orthomosaic to assess percentage coral coverage and substrate type. Six classes of substrate were identified: (1) mixed sediment, (2) mudstone, (3) hard rock, (4) dead coral framework, (5) live coral and (6) litter. Mixed sediment consisted of fine and mobile material such as sand, silt and loose mud, with some areas of coarser sand, empty shells and small coral fragments. Mudstone and consolidated muds were considered separate from mixed sediment and hard rock due to a firmer surface compared to mixed sediment, but its propensity to erosion over time (Carter et al. 2018), and the presence of burrows. Fine layers of mixed sediment overlying flat parts of mudstone were considered mudstone due to the local hydrodynamics leading to sporadic sediment cover.
This type of coverage quantification was undertaken to (1) recognise a value of coral cover that may induce a reef community or influence biodiversity with the potential to identify a VME discrimination point and (2) utilise dead coral cover percentage as an abiotic factor for analyses of within-reef communities to discriminate between rugosity and hard substrate provision as a driving factor and (3) gain a broad overview of the substrate composition at each subtransect.

\section{Statistics}

Linear regression analysis and Pearson correlation were used to identify a relationship between coral cover and rugosity metrics (VRM and rugosity index ratio). Data exploration on biodiversity metrics was undertaken following the guidelines of Zuur et al. (2007, 2009). We utilised generalised additive models (GAM) to investigate the relationship between the environmental variables (depth, VRM) and univariate biodiversity metrics (species richness, Shannon index $\left(H^{\prime}\right)$, total abundance and fish abundance). Collinearity was tested for by pairs plots and variance inflator factor (VIF). Depth and rugosity were not correlated, but substrate type (in terms of percentage cover) was found to strongly correlate $(>0.7$ Pearson correlation; VIF $>10$ ) with depth and rugosity and was therefore not included in the analysis. Normality was tested for by Shapiro-Wilk test, total and fish abundance were $\sqrt{ }$ and $\sqrt[3]{ }$ transformed to meet normality assumptions for use of a Gaussian family distribution. VRM and depth independently and combined were considered in the model building process and were assessed with corrected Akaike's information criterion value (AICc). Variance of the fitted residuals was inspected to ensure homogeneity. Variograms of the final models were explored to identify any evidence for spatial autocorrelation. Models were built using the package 'mgcv' in R ( $\mathrm{R}$ core team 2012).

Multivariate analysis was carried out in PRIMER V6 with the PERMANOVA + extension, on communities across all sub-transects and sub-transects with notable coral cover ( $>15 \%$ based on Rowden et al. 2017), to identify the drivers and the threshold where assemblage composition forms a distinct reef-associated community. Bray-Curtis similarity matrices of the communities were created after $\sqrt{ }$ transformation of the data. Group average clustering was undertaken in order to explore community similarities between transects and statistically tested by analysis of similarity (ANOSIM). Depth, rugosity and dead/live coral ratio were normalised, and Euclidean distance was used to create environmental similarity matrices. The relationship between each variable and the assemblage was investigated using a distance-based linear model (DISTLM). The 
DISTLM results were coupled with a distance-based redundancy analysis (dbRDA) to visualise the multidimensional spatial relationship. DISTLM tests each variable nominally which are then combined to create a multivariate structure. Final model choice was based on a stepwise AICc criteria method and BEST selection procedure.

\section{Results}

\section{Image acquisition}

A total of 40 reconstructions were produced utilising 8964 images and each sub-transect consisted on average of 224 ( \pm 13 SE) images (Table 1). The number of images depended on the speed of the ROV, ranging from approximately $0.06-0.24 \mathrm{~ms}^{-1}$, which was an appropriate speed to utilise stills from video without blur or excessive image overlap. Mean georeference error was $1.53 \mathrm{~m}$ $( \pm 0.07 \mathrm{~m} \mathrm{SE}$ ), which is within error estimates of USBL navigation (1\% of depth), and is relative to geographical location rather than within-model error (range $0.7-3 \mathrm{~mm}$ ). Continuous sampling along the entire ROV video transect was not always possible due to variations in ROV height inhibiting the camera view and monotone substrate that led to issues with camera positioning in the reconstructions. The mean reconstruction length was $26.8 \mathrm{~m}$ ( $\pm 0.6 \mathrm{~m} \mathrm{SE})$. As point to point USBL positioning was used to identify the $25 \mathrm{~m}$ sub-transect lengths, true transect lengths were often longer than $25 \mathrm{~m}$ (as much as $40 \mathrm{~m}$ ) due to an oscillating ROV path. In contrast, sub-transect A9 was only $18 \mathrm{~m}$ long but was retained for analysis to extend the range of rugosity measures as the coral cover was the highest. Sub-transect length had no effect on standardised species assemblages or species richness counts (considered as a variable in a BEST test and GAM, see supplement).

\section{Substrate classification}

Deeper sub-transects (A-F, I-N) were characterised by mudstone with sporadically interspersed pockets of mixed sediment (2-37\% cover) (Fig. 2). Sub-transects G and H were dominated by mixed sediment $(>70 \%$ cover) whilst sub-transect $\mathrm{O}$ was the deepest where coral framework was observed $(1071 \mathrm{~m})$, but consisted of all dead framework. The regular occurrence of coral started at sub-transect $\mathrm{U}$ and continued until A9 at depths between 770 and $935 \mathrm{~m}$. Coral cover ranged from 0 to $75 \%$ and mixed sediment usually covered most of the rest of the coral sub-transects. At shallower depths, mixed sediments were the dominant substrate (Fig. 2). Hard substrate (rock) and litter cover ( $\mathrm{n}=22$; fishing gear and plastic sheets mostly) was negligible.

\section{Coral rugosity}

VRM increased as neighbourhood size increased in an asymptotic curve (see supplement). Strong linear correlation with coral counts and \% cover was observed at neighbourhood sizes of $9.5 \times 9.5 \mathrm{~cm}$ and above (Pearson correlation plateaued at around 0.95). Beyond a neighbourhood size of $9.5 \times 9.5 \mathrm{~cm}$, analytical gains were negligible and thus $9.5 \times 9.5 \mathrm{~cm}$ pixel size was used for further analysis. Rugosity index ratio and VRM were strongly correlated $(r=0.92, p<0.05)$. VRM was visibly linked with coral colonies within each sub-transect whereby individual colonies observed in the orthomosaics (Fig. 3a) correlated with pixels indicating high VRM at all scales shown in Fig. 3. VRM and rugosity index were positively influenced by coral coverage $\left(R^{2}=0.914\right.$, $p<0.001 ; R^{2}=0.847, p<0.001$, respectively). VRM was chosen for the remaining analysis due to the slightly stronger relationship with coral cover than the rugosity index ratio (Fig. 4). In addition, VRM considers the full coverage of reconstruction.

\section{Biodiversity}

A total of 17,731 individual organisms (including coral colonies of which there were 5,145 observations) from 54 morphospecies were observed within the 40 sub-transect samples. Madrepora oculata (3541 colonies) and Lophelia pertusa (1572 colonies) were the two most prevalent reefbuilding scleractinians; only 32 colonies of Solenosmilia variabilis were observed.

VRM and depth influenced species richness, total abundance, Shannon-Wiener index (H') and fish abundance (Fig. 5, Table 2). Species richness increased with VRM, until about 0.07 VRM, when the increase plateaued (Fig. 5). The values of $H^{\prime}$ increased with VRM before decreasing after VRM of 0.05 (Fig. 5). Total epifauna abundance and fish abundance positively correlated with VRM (Fig. 5). Lepidion eques represented more than 50\% of the fish observed and of the $70 \mathrm{~L}$. eques observed, 54 were found within a few centimetres of coral structures, six near a non-reef structure (such as mudstone outcrops and ledges) and 10 were observed on flat structureless substrate. Depth was significant for $H^{\prime}$ and total abundance, appearing to mirror the general substrate patterns seen in Fig. 2. Spatial autocorrelation was not present in our dataset (see supplement), likely due to the inclusion of the depth variable that is intrinsically linked with latitude.

dbRDA plots revealed a partitioning between reef (>30\% coral framework cover) and non-reef communities (mixed sediment and mudrock habitats) (Fig. 6a). Distinct clustering of mixed sediment and rock mud sub-transects was observed but the assemblages still showed 30\% 
Table 1 Metadata of each sub-transect

\begin{tabular}{|c|c|c|c|c|c|c|c|c|c|}
\hline $\begin{array}{l}\text { Sub- } \\
\text { transects }\end{array}$ & $\begin{array}{l}\text { Total aligned } \\
\text { images }\end{array}$ & $\begin{array}{l}\text { Length } \\
\text { (m) }\end{array}$ & $\begin{array}{l}\text { Transect } \\
\text { time }\end{array}$ & $\begin{array}{l}\text { Number of dense } \\
\text { cloud points }\end{array}$ & $\begin{array}{l}\text { Georeference } \\
\text { error }(\mathrm{m})\end{array}$ & $\begin{array}{l}\text { Scale } \\
\text { error }(\mathrm{m})\end{array}$ & $\begin{array}{l}\text { DEM res }(\mathrm{mm} \\
\text { per pixel) }\end{array}$ & $\begin{array}{l}\text { Ortho (mm } \\
\text { per pixel) }\end{array}$ & $\begin{array}{l}\text { Mean } \\
\text { depth (m) }\end{array}$ \\
\hline A & 286 & 25.7 & $04: 45$ & $9,659,465$ & 1.22 & $\mathrm{n} / \mathrm{a}$ & 2.7 & 1.4 & -1071 \\
\hline B & 188 & 25 & 03:07 & $8,912,853$ & 1.32 & 0.012 & 2.8 & 1.4 & -1065 \\
\hline $\mathrm{C}$ & 287 & 26.9 & $04: 46$ & $10,894,879$ & 1.87 & 0.010 & 2.4 & 1.2 & -1059 \\
\hline $\mathrm{D}$ & 215 & 24.6 & $03: 34$ & $9,529,201$ & 1.80 & 0.012 & 2.7 & 1.3 & -1054 \\
\hline $\mathrm{E}$ & 307 & 25.6 & 05:06 & $10,350,493$ & 2.21 & 0.015 & 3.2 & 1.6 & -1042 \\
\hline $\mathrm{F}$ & 129 & 24.3 & 02:08 & $9,501,754$ & 1.60 & 0.012 & 2.6 & 1.3 & -1033 \\
\hline G & 152 & 26.9 & $02: 31$ & $10,134,821$ & 1.43 & 0.015 & 2.9 & 1.5 & -1032 \\
\hline $\mathrm{H}$ & 137 & 20 & $02: 16$ & $6,196,412$ & 1.99 & 0.022 & 2.8 & 1.4 & -1027 \\
\hline I & 243 & 26.6 & 04:02 & $11,079,272$ & 1.38 & 0.029 & 3.0 & 1.5 & -1016 \\
\hline $\mathrm{J}$ & 183 & 28.4 & 03:02 & $12,349,339$ & 1.30 & 0.009 & 2.3 & 1.2 & -1007 \\
\hline $\mathrm{K}$ & 174 & 29.2 & $02: 53$ & $13,307,670$ & 1.36 & 0.013 & 2.3 & 1.1 & -1001 \\
\hline $\mathrm{L}$ & 134 & 26.8 & $02: 13$ & $9,407,083$ & 1.59 & 0.016 & 2.6 & 1.3 & -998 \\
\hline M & 163 & 26 & $02: 42$ & $11,714,816$ & 1.75 & 0.017 & 2.3 & 1.1 & -997 \\
\hline $\mathrm{N}$ & 174 & 28.1 & $02: 53$ & $12,617,473$ & 1.21 & 0.010 & 2.3 & 1.2 & -993 \\
\hline $\mathrm{O}$ & 208 & 27.3 & $03: 27$ & $14,021,270$ & 1.48 & 0.013 & 2.4 & 1.2 & -985 \\
\hline Q & 274 & 22 & $04: 33$ & $11,236,523$ & 1.93 & 0.023 & 2.3 & 1.2 & -969 \\
\hline $\mathrm{R}$ & 211 & 25.5 & $03: 30$ & $12,467,613$ & 1.44 & 0.015 & 2.1 & 1.1 & -964 \\
\hline $\mathrm{S}$ & 161 & 23.8 & $02: 40$ & $11,317,261$ & 1.14 & 0.012 & 2.2 & 1.1 & -955 \\
\hline $\mathrm{T}$ & 137 & 26.9 & $02: 16$ & $9,764,789$ & 1.30 & 0.013 & 2.4 & 1.2 & -945 \\
\hline $\mathrm{U}$ & 230 & 29 & $03: 49$ & $13,893,585$ & 1.56 & 0.013 & 2.3 & 1.2 & -935 \\
\hline V & 114 & 22.3 & $01: 53$ & $8,261,666$ & 2.46 & 0.023 & 2.2 & 1.1 & -928 \\
\hline W & 152 & 23.7 & $02: 31$ & $10,299,492$ & 1.53 & 0.016 & 2.6 & 1.3 & -924 \\
\hline$X$ & 120 & 20.9 & 01:59 & $9,887,563$ & 2.55 & 0.029 & 2.1 & 1.0 & -915 \\
\hline $\mathrm{Y}$ & 215 & 30.3 & $03: 34$ & $13,884,492$ & 1.44 & 0.013 & 2.4 & 1.2 & -910 \\
\hline $\mathrm{Z}$ & 237 & 29.2 & 03:56 & $10,961,846$ & 1.68 & 0.017 & 2.8 & 1.4 & -898 \\
\hline A1 & 194 & 36.4 & $03: 13$ & $12,896,286$ & 1.25 & 0.014 & 2.8 & 1.4 & -895 \\
\hline A2 & 292 & 40.4 & $04: 51$ & $14,474,140$ & 1.29 & 0.018 & 3.6 & 1.8 & -868 \\
\hline A3 & 446 & 30.6 & $07: 25$ & $11,653,657$ & 1.63 & 0.011 & 3.5 & 1.8 & -852 \\
\hline A4 & 194 & 30.4 & $03: 13$ & $12,254,328$ & 0.93 & $\mathrm{n} / \mathrm{a}$ & 3.2 & 1.6 & -839 \\
\hline A5 & 274 & 20.7 & $04: 33$ & $14,974,612$ & 2.80 & 0.033 & 1.5 & 0.8 & -818 \\
\hline A6 & 344 & 32 & $05: 14$ & $20,569,788$ & 1.20 & 0.013 & 1.9 & 1.0 & -810 \\
\hline A7 & 329 & 28.6 & $05: 28$ & $18,821,126$ & 0.77 & 0.013 & 2.3 & 1.2 & -795 \\
\hline A8 & 455 & 23.2 & $07: 34$ & $13,659,740$ & 1.74 & 0.022 & 2.3 & 1.2 & -780 \\
\hline A9 & 180 & 17.6 & $02: 59$ & $8,434,800$ & 0.64 & 0.001 & 3.5 & 1.8 & -770 \\
\hline A10 & 317 & 27.1 & $05: 16$ & $13,649,729$ & 1.21 & 0.012 & 2.4 & 1.2 & -767 \\
\hline A11 & 237 & 27 & 03:56 & $11,298,246$ & 1.41 & 0.007 & 2.8 & 1.4 & -756 \\
\hline A12 & 223 & 25.5 & $03: 42$ & $8,461,635$ & 1.04 & 0.008 & 2.7 & 1.4 & -753 \\
\hline A13 & 125 & 22.7 & 02:04 & $11,625,973$ & 1.73 & 0.017 & 2.0 & 1.0 & -726 \\
\hline A14 & 317 & 23.8 & $05: 16$ & $10,488,154$ & 1.39 & 0.020 & 2.2 & 1.1 & -648 \\
\hline A15 & 206 & 22.9 & $03: 25$ & $9,965,094$ & 1.60 & 0.022 & 2.1 & 1.0 & -646 \\
\hline
\end{tabular}

similarity (Fig. 6), and sub-transects O and A11 communities were more akin to non-reef assemblages despite the presence of (mostly dead) coral structure (28 and 17\% coral cover, respectively), supported by ANOSIM results $(R=0.612 ; p=0.001)$. VRM accounted for $24 \%$ of the community structure, whilst depth accounted for $12 \%$ of the variation (Table 3, Fig. 6a).

There was little to no clustering of sub-transects with coral cover assemblages (Fig. 6b). The DistLM found that depth and VRM accounted for $42 \%$ of the assemblage 


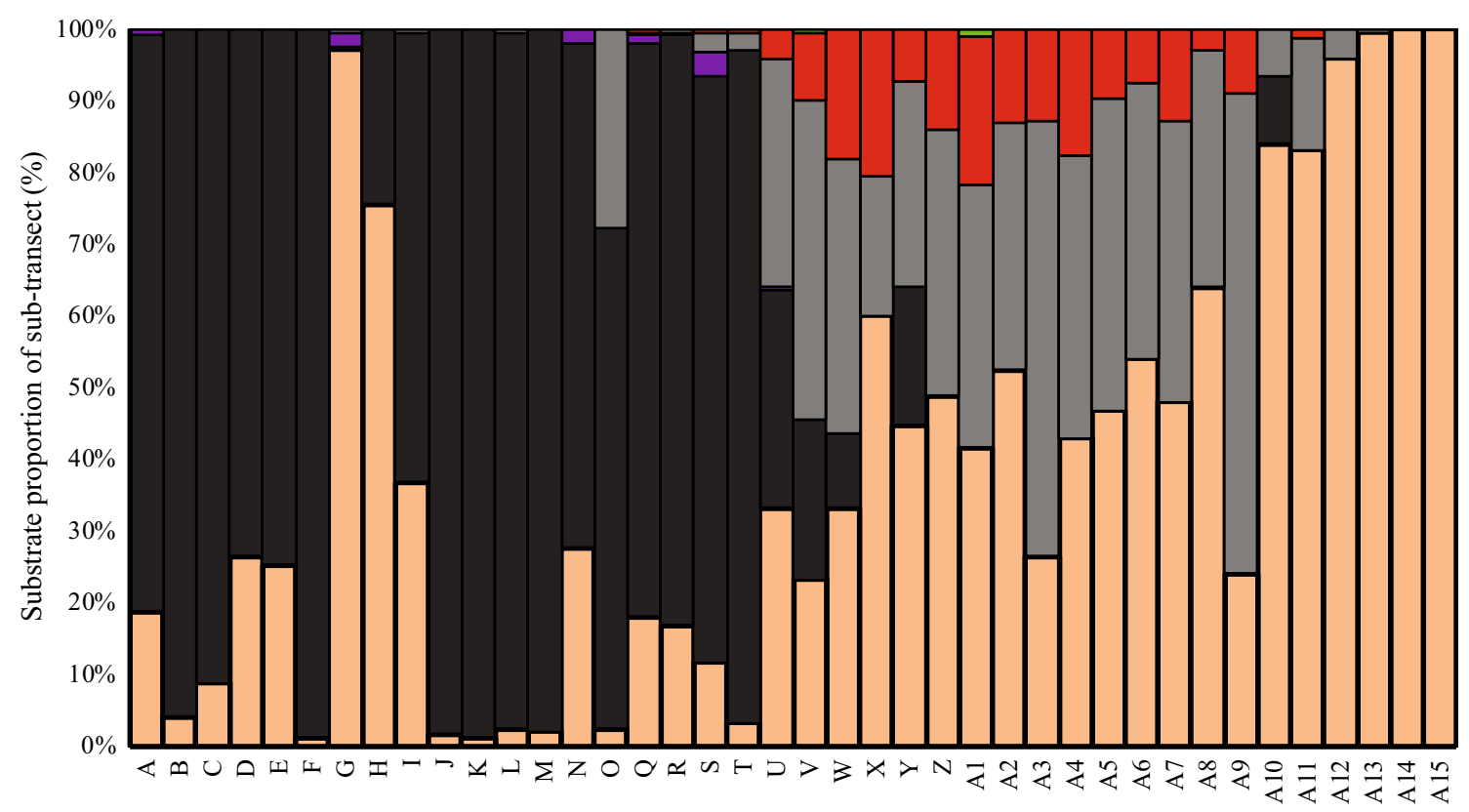

Sub-transect

$\square$ Mixed sediment $\quad$ Mudstone $\quad$ Rock $\quad$ Dead coral framework $\quad$ Live coral framework $\quad$ Litter

Fig. 2 Substrate cover for each sub-transect. Results from 250 randomised points within each orthomosaic

Fig. 3 Sub-transect $X$ as an example. a orthomosaic, b hillshade/digital elevation model and vector ruggedness measure values at $\mathbf{c} 1.5, \mathbf{d} 9.5$ and e $19.5 \mathrm{~cm}$ per pixel neighbourhood analysis
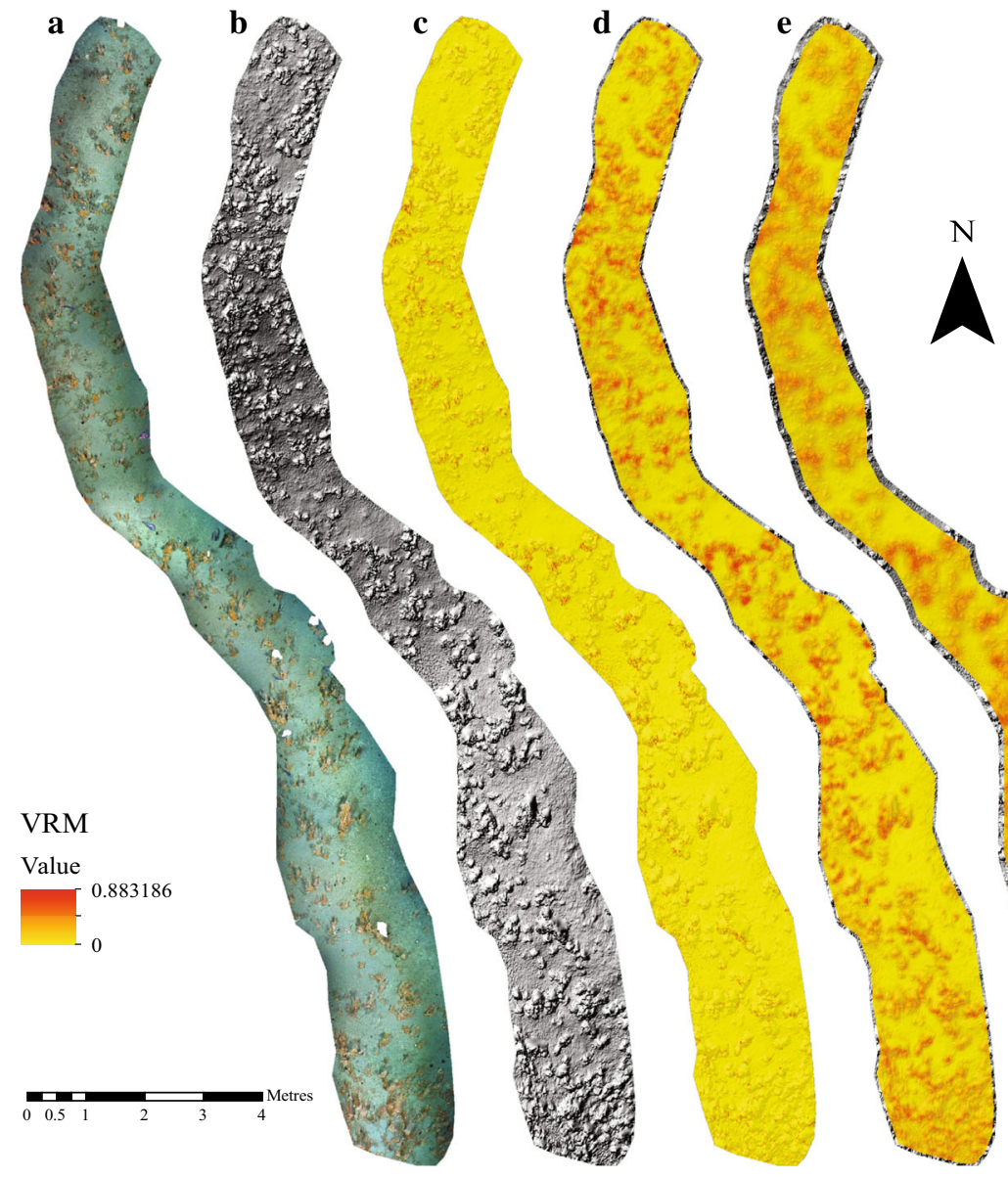

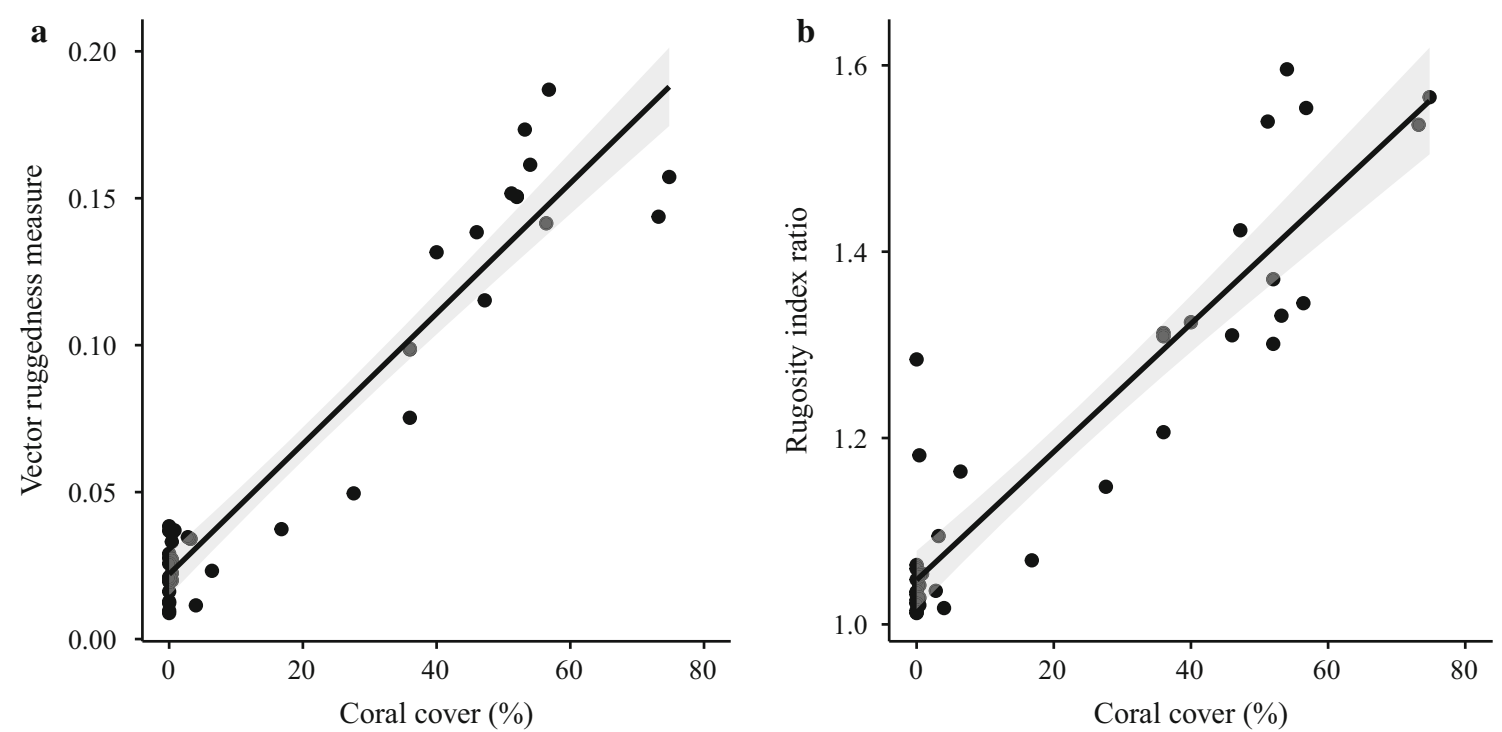

Fig. 4 Relationship of a vector ruggedness measure and $\mathbf{b}$ rugosity index ratio with cold-water coral cover

variation; depth was the strongest driving factor (26\%) with VRM playing a lesser role (15\%) (Table 3, Fig. 6b). The inclusion of dead/live coral ratio increased the variance explained to $46 \%$ (Table 4), though marginal tests deemed it non-significant, possibly due to small sample size.

\section{Discussion}

A strong linear relationship between coral cover and terrain complexity was evident, providing a strong quantitative relationship for the first time. The range of rugosity index values observed (up to 1.6) is comparable to global shallow-water coral reef rugosity index values (Graham and Nash 2013). In shallow-water coral reefs, scale-dependent rugosity (Richardson et al. 2017; Knudby et al. 2007), is a result of high coral morphology diversity (Burns et al., 2015) and intra-species morphological plasticity (Todd 2008). We did not observe comparable scale-dependent patterns as Explorer reef had relatively limited reef morphology diversity, though cauliflower-like structures found at other localities (e.g. De Clippele et al. 2018), or reefs with greater vertical relief may provide contrasting rugosity patterns.

Fine-scale structural complexity influenced biodiversity and benthic fauna abundance. However, due to a high level of collinearity we could not assess whether reef-induced complexity enhanced biodiversity or if provision of hard substrate and coral cover were the main driving factors. Yet, the reef structures observed in this study have a relatively low vertical profile, with very few colonies reaching $>50 \mathrm{~cm}$ tall. Thus, we suggest that reefs with greater vertical relief would display a wider rugosity range, in which case coral coverage percentage estimates become limited as an explanatory variable. Within the rugosity values observed, our data suggest that VRM influences species richness strongly to a certain point (approximately 0.07 VRM or 1.2 rugosity index equating to approximately 25-30\% coral cover), after which the structural complexity played a more limited role in promoting species richness. The strong positive relationship between species richness and rugosity at low rugosity values (indicating low coral cover) indicates sensitivity to fine-scale terrain complexity for deep-sea organisms. The increasing relationship between organism abundances and rugosity suggests reef structural complexity continued to influence inhabitant density beyond our measured VRM range. In addition to shelter provision and hydrodynamic regime diversity, increased rugosity is mathematically indicative of greater surface area and thus settling availability for sessile species. Due to the strong collinearity it is likely that rugosity represented the combined effect of reef rugosity and hard substrate availability, whilst depth was a proxy for many other explanatory variables (such as temperature and substrate type in this study).

Fish-coral association studies have shown the relationship is site and species specific on a broader scale (Biber et al. 2014), but our study shows more specifically that fish (notably Lepidion eques and Helicolenus dactylopterus; see supplement) utilised areas of reef-driven complexity. This is consistent with shallow-water reef research that identified a strong relationship between fish density and structural complexity (Graham and Nash 2013). Enhanced potential prey within the reef, likely at least in part influenced by rugosity as suggested by the high abundance of 

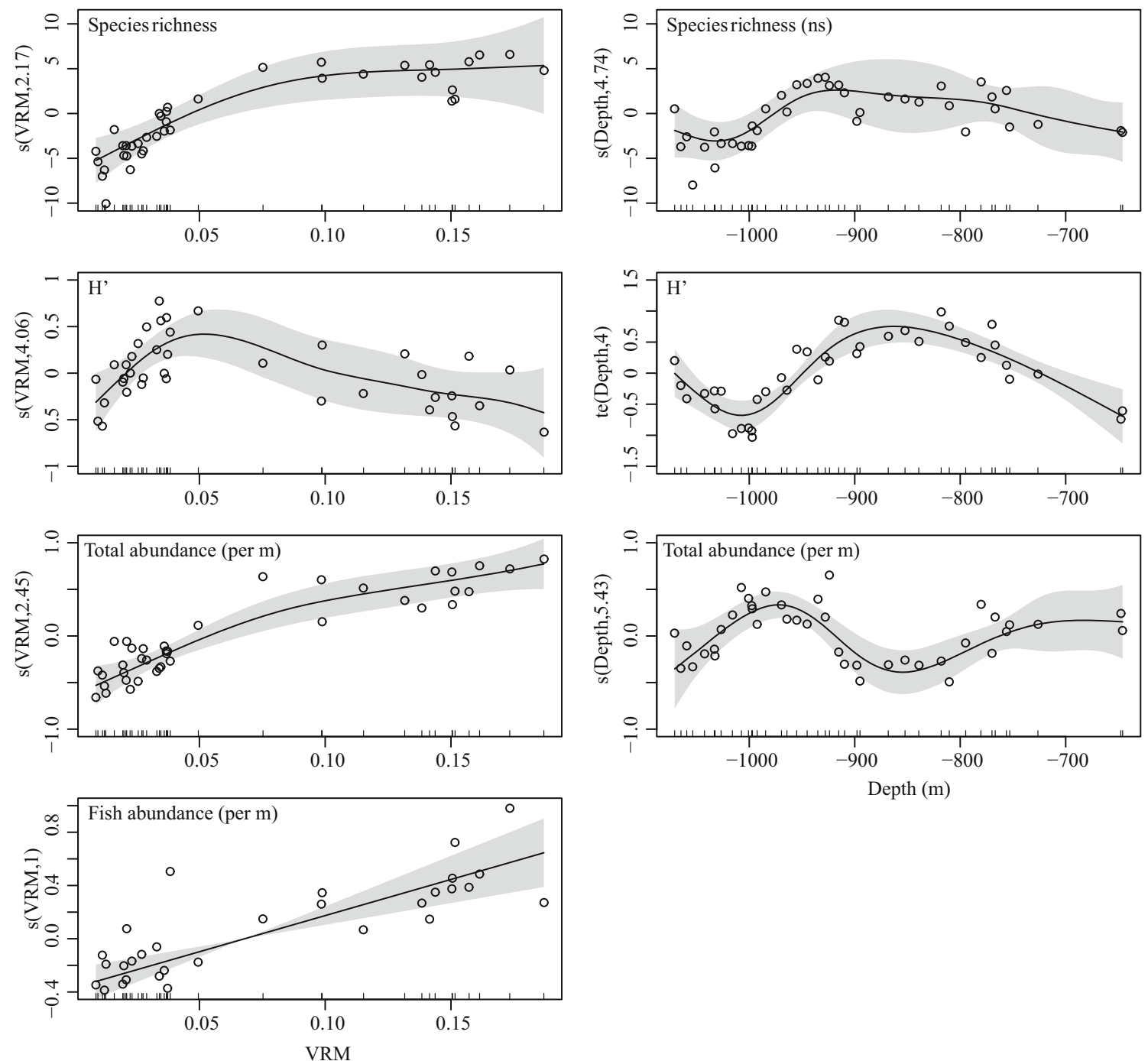

Fig. 5 GAM smoother outputs showing the relationship between vector ruggedness measure (VRM) and depth, and species richness, ShannonWiener index $\left(\mathrm{H}^{\prime}\right)$, total abundance and fish abundance

Table 2 Univariate biodiversity GAM results. Statistically significant $(p<0.05)$ in bold

\begin{tabular}{lllcccc}
\hline & Distribution family & VRM $p$ value & Depth $p$ value & $R^{2}$ adjusted & Deviance explained (\%) & Factors included \\
\hline Species richness & Poisson & $<\mathbf{0 . 0 0 1}$ & 0.0589 & 0.887 & 91.2 & VRM + Depth \\
H' & Gaussian & $<\mathbf{0 . 0 5}$ & $<\mathbf{0 . 0 0 1}$ & 0.711 & 77.2 & VRM +Depth \\
Total abundance (cuberoot) & Gaussian & $<\mathbf{0 . 0 0 1}$ & $<\mathbf{0 . 0 0 1}$ & 0.799 & 83.9 & VRM + Depth \\
Fish abundance (sqrt) & Gaussian & $<\mathbf{0 . 0 0 1}$ & & 0.398 & 44.1 & VRM \\
\hline
\end{tabular}

epifauna observed, could contribute to the positive fishrugosity relationship. However, we typically observed most $L$. eques swimming and $H$. dactylopterus resting within centimetres of coral colonies indicating their behaviour was linked to the physical structure, likely for shelter and reproduction (Costello et al. 2005; Husebø et al. 2002; Henry et al. 2013; Corbera et al. 2019).
Community assemblages in sub-transects with coral cover were driven by depth and rugosity with limited influence from the proportion of live/dead coral framework. Whilst we suggest some species such as mobile invertebrates are likely to benefit from structural complexity (Stevenson et al. 2015) independent of live/dead coral ratio, certainly for some sessile species such as 


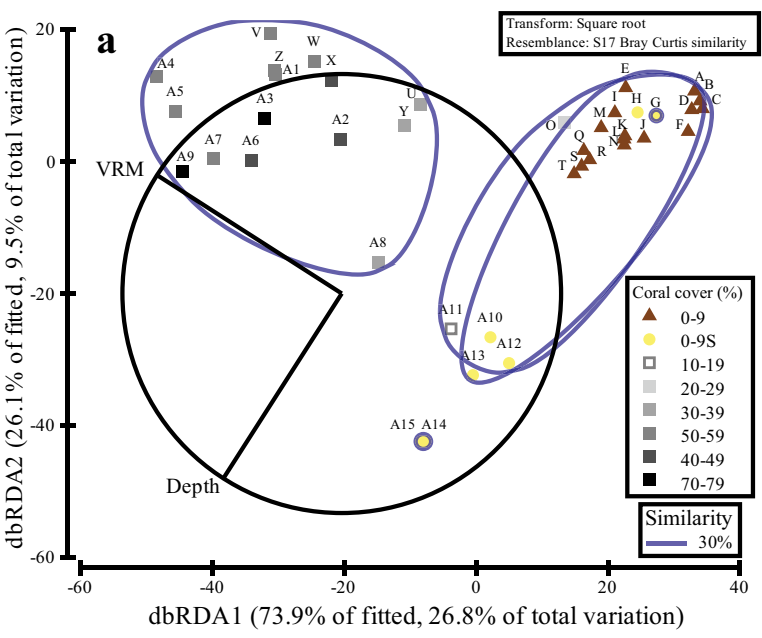

Fig. 6 dbRDA plots based upon DistLM results (Table 3), with significant abiotic overlay. a All transects. b Transects with $>15 \%$ coral coverage. $30 \%$ similarity circles are based upon group average clustering. Coral cover as a percentage with corresponding grey

Table 3 Sequential test results from distance-based linear model. All habitat community refers to Fig. 6a, and within-reef community refers to Fig. $6 \mathrm{~b}$

\begin{tabular}{lclll}
\hline Variable & Pseudo- $F$ & $p$ & Prop & Cumulative \\
\hline All habitat & communities & & & \\
VRM & 11.994 & $<0.001$ & 0.240 & 0.240 \\
Depth & 7.106 & $<0.001$ & 0.122 & 0.362 \\
Coral reef & community & & & \\
Depth & 5.471 & $<0.01$ & 0.267 & 0.267 \\
VRM & 3.693 & $<0.01$ & 0.153 & 0.420 \\
\hline
\end{tabular}

Table 4 Best model solutions for explaining community structure of transects with reef patches (Fig. 6b)

\begin{tabular}{llll}
\hline AICc & $R^{2}$ & RSS & Selections \\
\hline 121.35 & 0.420 & 13,496 & Depth + VRM \\
122.34 & 0.267 & 17,056 & Depth \\
123.48 & 0.465 & 12,457 & Depth + VRM + \% dead coral
\end{tabular}

Actinaria spp. the hard substrate provided by the dead coral framework seemed essential to their existence. However, the composition of coral framework was dominated by dead coral skeleton (49-100\% dead), providing no distinct live coral dominated habitat and associated assemblages for comparison. This is consistent with Mortensen et al. (1995) who identified little difference between living and dead coral zone megafauna diversity from comparable $10 \mathrm{~m}$ video transects, citing the availability of dead coral framework within living reefs on the Norwegian shelf,
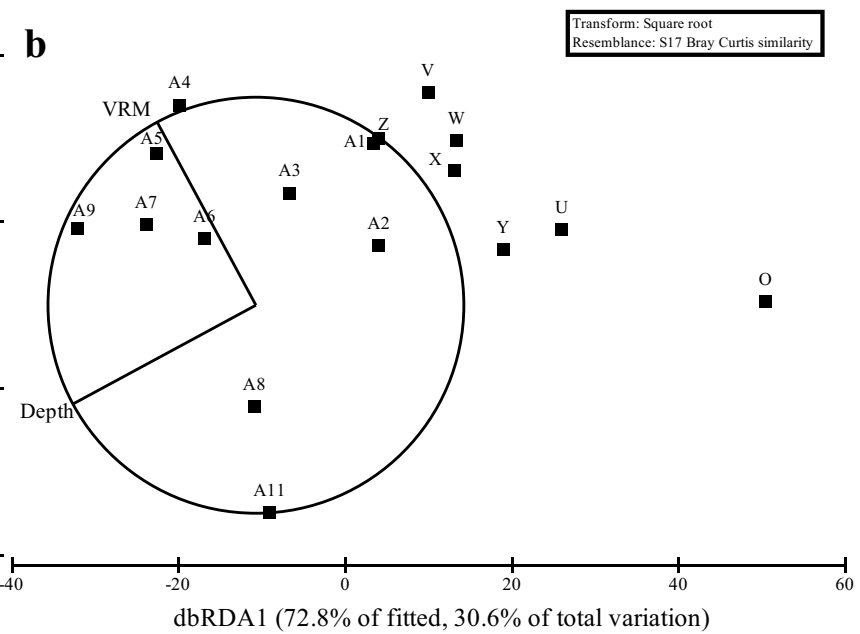

gradients to match. Brown triangle represents $0-9 \%$ coral coverage with mudstone dominating the rest, yellow circle signify $0-9 \%$ coral cover with mixed sediment dominating the rest. Letters refer to subtransect identity

though the threshold for living reef classification was minimal at $10 \%$ live coral cover. Conversely, De Clippele et al. (2018) noted abundances of sponge species (megafauna) differed depending on the proportion of live coral cover from video data, exemplifying that proportion of dead coral cover can influence some groups, though few sponges were observed at Explorer Canyon to enable testing of this association. Furthermore, Lessard-Pilon et al. (2010), observed that live/dead coral ratio influenced the trophic level of inhabitants suggesting a community structure difference. However, this was compared between different reef sites suggesting different inter- and intra-reef specific relationships or that local rugosity was an unquantified underlying contributing factor. This ambiguity highlights the need for further research to establish if this relationship is ecosystem wide and whether a larger live/dead coral ratio range may be required to further discriminate the influence of dead vs live coral and structural complexity. Overall, within reef-influenced sub-transects, assemblage heterogeneity was present and was influenced by structural complexity and depth (and its dependents).

The techniques presented provide a novel method to quantify the role of cold-water coral in enhancing biodiversity in the deep sea on a scale of metres. Areas of high rugosity and coral cover harboured distinct communities with increased diversity, and it appeared relatively little coral cover is required to influence the community. The cluster analysis grouped sub-transects A11 and O (17 and $28 \%$ coral cover, respectively) distinctly from coral communities, suggesting coral cover between $28 \%$ (sub-transect $\mathrm{O}$ ) and $36 \%$ (sub-transects $\mathrm{U}$ and A8) is representative of a threshold at which coral reef communities become established and distinct. Coral cover of approximately $30 \%$ 
may represent the point at which a group of coral colonies form a distinct habitat, at least on a scale of $10 \mathrm{~s}$ of metres, and support classification as a VME from imagery in Explorer Canyon. Species richness also plateaued at about $30 \%$ coral cover (0.07VRM) further supporting the suggestion that this proportion of coral represents the point at which a stable habitat is formed. This is also consistent with the position of the sub-transect in the reef, whereby distinct communities were found in the densest part of the reef at intermediate depths, with reef edges and low coral cover areas not harbouring highly distinct communities.

The implications for VME assignment are that in the absence of a large reef, it is unlikely that single colonies or very low coral coverage will support a distinct reef assemblage, thus may not fulfil the requirements for assignment. Nonetheless, if environmental conditions persist, a substantial reef may develop, meaning such areas could be considered prospective reef VME which should be taken into consideration for conservation. Furthermore, although the associated assemblages were not distinct, low coral coverage and associated rugosity still positively influenced univariate indices, and thus could still be considered biodiversity hotspots. Due to these results being based on a single reef over one time period, further research and wider application of our methods is recommended. Furthermore, these results are specific to the Explorer Canyon reef, and it is unknown how well these results would translate to different cold-water coral reefs.

Our results demonstrate how we can utilise SfM to identify fine-scale ecological drivers and quantify coldwater coral structural complexity. Furthermore, the orthomosaics produced can be useful to create high-resolution substrate and habitat maps over larger areas (Lim et al. 2017; Conti et al. 2019), and the 3D models used to measure coral growth rates (Bennecke et al. 2016). This demonstrates the effectiveness of this methodology to monitor reef structures that are vulnerable to anthropogenic impacts such as fishing and shoaling aragonite saturation (Jackson et al. 2014).

To conclude, our results suggest fine-scale rugosity has an important role in community dynamics, which should be considered when interpreting broader-scale ecological information as ecological patterns relate to different variables at different scales, requiring multi-scale investigation. We present proof of concept that SfM can provide novel information on localised influential abiotic variables and show that reef diversity and assemblage composition is driven by intricate fine-scale drivers beyond presence and absence of coral, furthering our knowledge of cold-water coral reef ecology.

Acknowledgements This work was undertaken as part of the European Research Council (Grant No. 258482) funded CODEMAP project (Complex Deep-sea Environments: Mapping habitat heterogeneity As Proxy for biodiversity). The JC125 cruise was funded by CODEMAP and the NERC MAREMAP programme, with additional financial support from DEFRA. D. Price was supported by the Natural Environmental Research Council [grant number NE/N012070/1]. V. Huvenne was supported by CODEMAP, the MAREMAP programme and the NERC CLASS project (grant number NE/R015953/ 1). We thank the captain and crew of the RRS James Cook for their assistance during the expedition. The authors acknowledge the use of the IRIDIS High Performance Computing Facility, and associated support services at the University of Southampton. Finally, we are grateful to the three anonymous reviewers who gave constructive feedback, improving this manuscript.

\section{Compliance with ethical standards}

Conflict of interest On behalf of all authors, the corresponding author states that there is no conflict of interest.

Open Access This article is distributed under the terms of the Creative Commons Attribution 4.0 International License (http://crea tivecommons.org/licenses/by/4.0/), which permits unrestricted use, distribution, and reproduction in any medium, provided you give appropriate credit to the original author(s) and the source, provide a link to the Creative Commons license, and indicate if changes were made.

\section{References}

Addamo AM, Vertino A, Stolarski J, García-Jiménez R, Taviani M, Machordom A (2016) Merging scleractinian genera: the overwhelming genetic similarity between solitary Desmophyllum and colonial Lophelia. BMC Evol Biol 16:108

Althaus F, Williams A, Schlacher TA, Kloser RJ, Green MA, Barker BA, Bax NJ, Brodie P, Schlacher-Hoenlinger MA (2009) Impacts of bottom trawling on deep-coral ecosystems of seamounts are long-lasting. Mar Ecol Prog Ser 397:279-294

Aslam T, Hall RA, Dye SR (2018) Internal tides in a dendritic submarine canyon. Prog Oceanogr 169:20-32

Bennecke S, Kwasnitschka T, Metaxas A, Dullo WC (2016) In situ growth rates of deep-water octocorals determined from $3 \mathrm{D}$ photogrammetric reconstructions. Coral Reefs 35:1227-1239

Biber MF, Duineveld GCA, Lavaleye MSS, Davies AJ, Bergman MJN, van den Beld IMJ (2014) Investigating the association of fish abundance and biomass with cold-water corals in the deep Northeast Atlantic Ocean using a generalised linear modelling approach. Deep-Sea Res Pt Ii 99:134-145

Bourque JR, Demopoulos AWJ (2018) The influence of different deep-sea coral habitats on sediment macrofaunal community structure and function. Peerj 6:e5276

Boxshall AJ (2000) The importance of flow and settlement cues to larvae of the abalone, Haliotis rufescens Swainson. J Exp Mar Biol Ecol 254:143-167

Buhl-Mortensen L, Vanreusel A, Gooday AJ, Levin LA, Priede IG, Mortensen PB, Gheerardyn H, King NJ, Raes M (2010) Biological structures as a source of habitat heterogeneity and biodiversity on the deep ocean margins. Mar Ecol 31:21-50

Burns JHR, Delparte D, Gates RD, Takabayashi M (2015) Integrating structure-from-motion photogrammetry with geospatial software as a novel technique for quantifying $3 \mathrm{D}$ ecological characteristics of coral reefs. Peerj 3:e1077

Carter GD, Huvenne VA, Gales JA, Iacono CL, Marsh L, OugierSimonin A, Robert K, Wynn RB (2018) Ongoing evolution of 
submarine canyon rockwalls; examples from the Whittard Canyon, Celtic Margin (NE Atlantic). Prog Oceanogr 169:79-88

Conti L, Lim A, Wheeler AJ (2019) High resolution mapping of a cold water coral mound. Sci Rep-Uk 9:1016

Corbera G, Lo Iacono C, Gràcia E, Grinyó J, Pierdomenico M, Huvenne VAI, Aguilar R, Gili J-M (2019) Ecological characterisation of a Mediterranean cold-water coral reef: Cabliers Coral Mound Province (Alboran Sea, western Mediterranean). Prog Oceanogr 175:245-262

Cordes EE, McGinley MP, Podowski EL, Becker EL, Lessard-Pilon S, Viada ST, Fisher CR (2008) Coral communities of the deep Gulf of Mexico. Deep Sea Res Part 1 Oceanogr Res Pap 55:777-787

Costello MJ, McCrea M, Freiwald A, Lundalv T, Jonsson L, Bett BJ, van Weering TCE, de Haas H, Roberts JM, Allen D (2005) Role of cold-water Lophelia pertusa coral reefs as fish habitat in the NE Atlantic. Erlangen Earth C Ser:771-805

Davies AJ, Roberts JM, Hall-Spencer J (2007) Preserving deep-sea natural heritage: Emerging issues in offshore conservation and management. Biol Conserv 138:299-312

Davies AJ, Duineveld GCA, Lavaleye MSS, Bergman MJN, van Haren H, Roberts JM (2009) Downwelling and deep-water bottom currents as food supply mechanisms to the cold-water coral Lophelia pertusa (Scleractinia) at the Mingulay Reef complex. Limnol Oceanogr 54:620-629

Davies JS, Howell KL, Stewart HA, Guinan J, Golding N (2014) Defining biological assemblages (biotopes) of conservation interest in the submarine canyons of the South West Approaches (offshore United Kingdom) for use in marine habitat mapping. Deep Sea Res Part 2 Top Stud Oceanogr 104:208-229

De Clippele LH, Huvenne VAI, Orejas C, Lundalv T, Fox A, Hennige SJ, Roberts JM (2018) The effect of local hydrodynamics on the spatial extent and morphology of cold-water coral habitats at Tisler Reef, Norway. Coral Reefs 37:253-266

De Clippele LH, Gafeira J, Robert K, Hennige S, Lavaleye MS, Duineveld GCA, Huvenne VAI, Roberts JM (2017) Using novel acoustic and visual mapping tools to predict the small-scale spatial distribution of live biogenic reef framework in cold-water coral habitats. Coral Reefs 36:255-268

De Mol L, Van Rooij D, Pirlet H, Greinert J, Frank N, Quemmerais F, Henriet JP (2011) Cold-water coral habitats in the Penmarc'h and Guilvinec Canyons (Bay of Biscay): Deep-water versus shallow-water settings. Mar Geol 282:40-52

Duineveld GCA, Jeffreys RM, Lavaleye MSS, Davies AJ, Bergman MJN, Watmough T, Witbaard R (2012) Spatial and tidal variation in food supply to shallow cold-water coral reefs of the Mingulay Reef complex (Outer Hebrides, Scotland). Mar Ecol Prog Ser 444:97-115

FAO (2009) International Guidelines for the Management of DeepSea Fisheries in the High Seas. Report of the Technical Consultation on International Guidelines for the Management of Deep-sea Fisheries in the High Seas, Rome, 4-8 February and 25-29 August 2008. FAO Fisheries and Aquaculture Report

Fossa JH, Mortensen PB, Furevik DM (2002) The deep-water coral Lophelia pertusa in Norwegian waters: distribution and fishery impacts. Hydrobiologia 471:1-12

Foubert A, Huvenne V, Wheeler A, Kozachenko M, Opderbecke J, Henriet J-P (2011) The Moira Mounds, small cold-water coral mounds in the Porcupine Seabight, NE Atlantic: Part BEvaluating the impact of sediment dynamics through highresolution ROV-borne bathymetric mapping. Mar Geol 282:65-78

Friedlander AM, Parrish JD (1998) Habitat characteristics affecting fish assemblages on a Hawaiian coral reef. J Exp Mar Biol Ecol 224:1-30
Graham NAJ, Nash KL (2013) The importance of structural complexity in coral reef ecosystems. Coral Reefs 32:315326

Gratwicke B, Speight MR (2005) The relationship between fish species richness, abundance and habitat complexity in a range of shallow tropical marine habitats. J Fish Biol 66:650-667

Hall RA, Aslam T, Huvenne VA (2017) Partly standing internal tides in a dendritic submarine canyon observed by an ocean glider. Deep Sea Res Part 1 Oceanogr Res 126:73-84

Harii S, Kayanne H (2002) Larval settlement of corals in flowing water using a racetrack flume. Mar Technol Soc J 36:76-79

Hennige S, Wicks L, Kamenos N, Perna G, Findlay H, Roberts J (2015) Hidden impacts of ocean acidification to live and dead coral framework. Proc R Soc B 282:20150990

Henry L-A, Roberts JM (2007) Biodiversity and ecological composition of macrobenthos on cold-water coral mounds and adjacent off-mound habitat in the bathyal Porcupine Seabight, NE Atlantic. Deep Sea Res Part 1 Oceanogr Res Pap 54:654672

Henry L-A, Roberts JM (2015) Global biodiversity in cold-water coral reef ecosystems. In: Rossi S, Bramanti L, Gori A, Orejas C (eds) Marine animal forests. The ecology of benthic biodiversity hotspots, Springer, Netherlands, pp 235-256

Henry L-A, Navas JM, Hennige SJ, Wicks LC, Vad J, Roberts JM (2013) Cold-water coral reef habitats benefit recreationally valuable sharks. Biol Conserv 161:67-70

Husebø Å, Nøttestad L, Fosså J, Furevik D, Jørgensen S (2002) Distribution and abundance of fish in deep-sea coral habitats. Hydrobiologia 471:91-99

Huvenne VAI, Bett BJ, Masson DG, Le Bas TP, Wheeler AJ (2016a) Effectiveness of a deep-sea cold-water coral Marine Protected Area, following eight years of fisheries closure. Biol Conserv 200:60-69

Huvenne VAI, Wynn RB, Gales JA (2016b) RRS James Cook Cruise 124-125-126 09 Aug-12 Sep 2016. CODEMAP2015: Habitat Mapping and ROV Vibrocorer Trials Around Whittard Canyon and Haig Fras

Huvenne VAI, Tyler PA, Masson DG, Fisher EH, Hauton C, Huhnerbach V, Le Bas TP, Wolff GA (2011) A Picture on the Wall: Innovative Mapping Reveals Cold-Water Coral Refuge in Submarine Canyon. Plos One 6:e28755

Jackson EL, Davies AJ, Howell KL, Kershaw PJ, Hall-Spencer JM (2014) Future-proofing marine protected area networks for cold water coral reefs. ICES J. Mar. Sci. 71:2621-2629

Jensen A, Frederiksen R (1992) The Fauna Associated with the BankForming Deep-Water Coral Lophelia-Pertusa (Scleractinaria) on the Faroe Shelf. Sarsia 77:53-69

Johnson-Roberson M, Pizarro O, Williams SB, Mahon I (2010) Generation and Visualization of Large-Scale Three-Dimensional Reconstructions from Underwater Robotic Surveys. J Field Robot 27:21-51

Jones CG, Lawton JH, Shachak M (1994) Organisms as ecosystem engineers. Ecosystem management. Springer, New York, NY, pp 130-147

Jonsson LG, Nilsson PG, Floruta F, Lundalv T (2004) Distributional patterns of macro- and megafauna associated with a reef of the cold-water coral Lophelia pertusa on the Swedish west coast. Mar Ecol Prog Ser 284:163-171

Knudby A, LeDrew E, Newman C (2007) Progress in the use of remote sensing for coral reef biodiversity studies. Prog Phys Geog 31:421-434

Kwasnitschka T, Hansteen TH, Devey CW, Kutterolf S (2013) Doing fieldwork on the seafloor: Photogrammetric techniques to yield 3D visual models from ROV video. Comput Geosci-Uk $52: 218-226$ 
Leon JX, Roelfsema CM, Saunders MI, Phinn SR (2015) Measuring coral reef terrain roughness using 'Structure-from-Motion' close-range photogrammetry. Geomorphology 242:21-28

Lessard-Pilon SA, Podowski EL, Cordes EE, Fisher CR (2010) Megafauna community composition associated with Lophelia pertusa colonies in the Gulf of Mexico. Deep Sea Res Part 2 Top Stud Oceanogr 57:1882-1890

Lim A, Wheeler AJ, Arnaubec A (2017) High-resolution facies zonation within a cold-water coral mound: The case of the Piddington Mound, Porcupine Seabight, NE Atlantic. Mar Geol 390:120-130

Lim A, Huvenne VAI, Vertino A, Spezzaferri S, Wheeler AJ (2018) New insights on coral mound development from groundtruthed high-resolution ROV-mounted multibeam imaging. Mar Geol 403:225-237

Lo Iacono C, Robert K, Gonzalez-Villanueva R, Gori A, Gili J-M, Orejas C (2018) Predicting cold-water coral distribution in the Cap de Creus Canyon (NW Mediterranean): Implications for marine conservation planning. Prog Oceanogr 169:169-180

Mienis F, de Stigter HC, White M, Dulneveld GCA, de Haas H, van Weering TCE (2007) Hydrodynamic controls on cold-water coral growth and carbonate-mound development at the SW and SE rockall trough margin, NE Atlantic ocean. Deep Sea Res Part 1 Oceanogr Res Pap 54:1655-1674

Ministerial order. 2013. The Canyons Marine Conservation Zone Designation Order, Ministerial order 2013 No. 4, [Accessed 2018/08/29: http://www.legislation.gov.uk/ukmo/2013/4/pdfs/ ukmo_20130004_en.pdf]

Mortensen PB, Fosså JH (2006) Species diversity and spatial distribution of invertebrates on deep-water Lophelia reefs in Norway. Proc 10th Int Coral Reef Symp 1:1849-1868

Mortensen PB, Hovland M, Brattegard T, Farestveit R (1995) Deep water bioherms of the scleractinian coral Lophelia pertusa (L.) at $64 \mathrm{~N}$ on the Norwegian shelf: structure and associated megafauna. Sarsia 80:145-158

Orejas C, Gori A, Lo Iacono C, Puig P, Gili JM, Dale MRT (2009) Cold-water corals in the Cap de Creus canyon, northwestern Mediterranean: spatial distribution, density and anthropogenic impact. Mar Ecol Prog Ser 397:37-51

Orejas C, Gori A, Rad-Menendez C, Last KS, Davies AJ, Beveridge CM, Sadd D, Kiriakoulakis K, Witte U, Roberts JM (2016) The effect of flow speed and food size on the capture efficiency and feeding behaviour of the cold-water coral Lophelia pertusa. J Exp Mar Biol Ecol 481:34-40

Porter M, Inall ME, Hopkins J, Palmer MR, Dale AC, Aleynik D, Barth JA, Mahaffey C, Smeed DA (2016) Glider observations of enhanced deep water upwelling at a shelf break canyon: A mechanism for cross-slope carbon and nutrient exchange. J Geophys Res Oceans 121:7575-7588

Purser A, Larsson AI, Thomsen L, van Oevelen D (2010) The influence of flow velocity and food concentration on Lophelia pertusa (Scleractinia) zooplankton capture rates. J Exp Mar Bio Ecol 395:55-62

Purser A, Orejas C, Gori A, Tong RJ, Unnithan V, Thomsen L (2013) Local variation in the distribution of benthic megafauna species associated with cold-water coral reefs on the Norwegian margin. Cont Shelf Res 54:37-51

Purser A, Marcon Y, Dreutter S, Hoge U, Sablotny B, Hehemann L, Lemburg J, Dorschel B, Biebow H, Boetius A (2018) Ocean Floor Observation and Bathymetry System (OFOBS): A new Towed Camera/Sonar System for Deep-Sea Habitat Surveys. IEEE Journal of Oceanic Engineering 44:87-99

Richardson LE, Graham NAJ, Hoey AS (2017) Cross-scale habitat structure driven by coral species composition on tropical reefs. Sci Rep-Uk 7:7557
Robert K, Jones DO, Tyler PA, Van Rooij D, Huvenne VA (2015) Finding the hotspots within a biodiversity hotspot: fine-scale biological predictions within a submarine canyon using highresolution acoustic mapping techniques. Mar Ecol 36:1256-1276

Robert K, Huvenne VAI, Georgiopoulou A, Jones DOB, Marsh L, Carter GDO, Chaumillon L (2017) New approaches to highresolution mapping of marine vertical structures. Sci Rep-Uk 7:7557

Roberts JM, Peppe OC, Dodds LA, Mercer DJ, Thomson WT, Gage JD, Meldrum DT (2005) Monitoring environmental variability around cold-water coral reefs: the use of a benthic photolander and the potential of seafloor observatories. In: Freiwald A, Roberts JM (eds) Cold-water corals and ecosystems. Springer, Berlin, pp 483-502

Rowden AA, Anderson OF, Georgian SE, Bowden DA, Clark MR, Pallentin A, Miller A (2017) High-Resolution Habitat Suitability Models for the Conservation and Management of Vulnerable Marine Ecosystems on the Louisville Seamount Chain, South Pacific Ocean. Front Mar Sci 4:335

Sappington JM, Longshore KM, Thompson DB (2007) Quantifying landscape ruggedness for animal habitat analysis: a case study using bighorn sheep in the Mojave Desert. J Wildl Manage 71:1419-1426

Söffker M, Sloman KA, Hall-Spencer JM (2011) In situ observations of fish associated with coral reefs off Ireland. Deep Sea Res Part 1 Oceanogr Res Pap 58:818-825

Stevenson A, Mitchell FJG, Davies JS (2015) Predation has no competition: factors influencing space and resource use by echinoids in deep-sea coral habitats, as evidenced by continuous video transects. Mar Ecol-Evol Persp 36:1454-1467

Storlazzi CD, Dartnell P, Hatcher GA, Gibbs AE (2016) End of the chain? Rugosity and fine-scale bathymetry from existing underwater digital imagery using structure-from-motion (SfM) technology. Coral Reefs 35:889-894

Todd PA (2008) Morphological plasticity in scleractinian corals. Biol Rev 83:315-337

Turley C, Roberts J, Guinotte J (2007) Corals in deep-water: will the unseen hand of ocean acidification destroy cold-water ecosystems? Coral Reefs 26:445-448

van Oevelen D, Duineveld G, Lavaleye M, Mienis F, Soetaert K, Heip CHR (2009) The cold-water coral community as a hot spot for carbon cycling on continental margins: A food-web analysis from Rockall Bank (northeast Atlantic). Limnol Oceanogr 54:1829-1844

Vertino A, Savini A, Rosso A, Di Geronimo I, Mastrototaro F, Sanfilippo R, Gay G, Etiope G (2010) Benthic habitat characterization and distribution from two representative sites of the deep-water SML Coral Province (Mediterranean). Deep Sea Res Part 2 Top Stud Oceanogr 57:380-396

Vlasenko V, Stashchuk N, Inall ME, Hopkins JE (2014) Tidal energy conversion in a global hot spot: On the 3-D dynamics of baroclinic tides at the Celtic Sea shelf break. J Geophys Res Oceans 119:3249-3265

Wheeler AJ, Beyer A, Freiwald A, de Haas H, Huvenne VAI, Kozachenko M, Olu-Le Roy K, Opderbecke J (2007) Morphology and environment of cold-water coral carbonate mounds on the NW European Margin. Int J Earth Sci 96:37-56

Wilson JB (1979) Patch Development of the Deep-Water Coral Lophelia-Pertusa (L) on Rockall Bank. J Mar Biol Assoc Uk 59:165-177

Wilson SK, Graham NAJ, Polunin NVC (2007) Appraisal of visual assessments of habitat complexity and benthic composition on coral reefs. Mar Biol 151:1069-1076

Wright D, Lundblad E, Larkin E, Rinehart R, Murphy J, CaryKothera L, Draganov K (2005) ArcGIS benthic terrain modeler. Oregon State University, Corvallis, OR, USA 
Young GC, Dey S, Rogers AD, Exton D (2017) Cost and timeeffective method for multiscale measures of rugosity, fractal dimension, and vector dispersion from coral reef 3D models. Plos One 12:e0175341

Zuur AF, Ieno EN, Walker NJ, Saveliev AA, Smith GM. (2009) Mixed Effects Models and Extensions in Ecology with R. Highland Statistics Limited Newburgh
Zuur A, Ieno EN, Smith GM (2007) Analyzing ecological data. Springer Science \& Business Media

Publisher's Note Springer Nature remains neutral with regard to jurisdictional claims in published maps and institutional affiliations. 